\section{Pura López Colomé y su traducción del canon femenino de la poesía en lengua inglesa Xittlaitt Rodríguez-Mendoza}

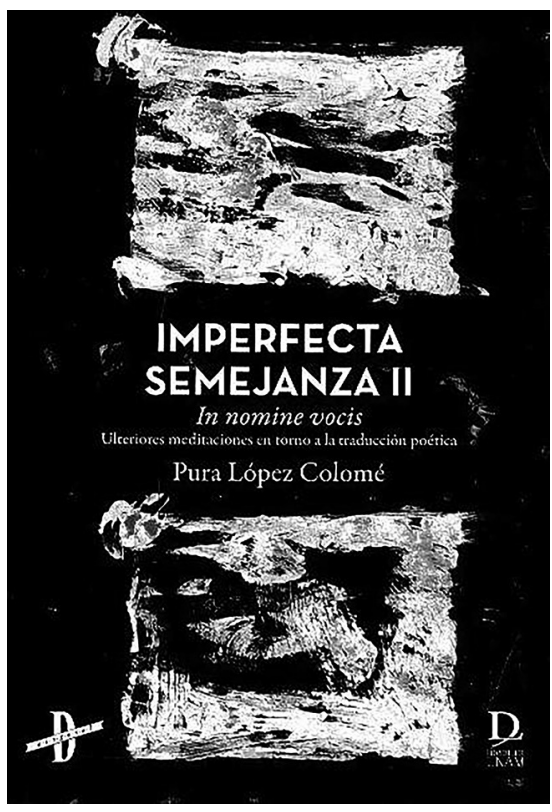

Pura López Colomé, Imperfecta semejanza II. In nomine vocis. Ulteriores meditaciones en torno a la traducción poética, ISBN: 9786073008853, México, Literatura UNAM, 2018, 332 pp.
Los traductores-poetas, los poetas-traductores somos mineros cuyo faro es la linterna propia al centro de la mente, al centro del corazón, en el descenso al yacimiento del tesoro universal. O..." Con estas palabras, la poeta y traductora mexicana Pura López Colomé (1952) termina el proemio de Imperfecta semejanza II. In nomine vocis. Ulteriores meditaciones en torno a la traducción poética, publicado en 2018 en la colección de ensayo literario Diagonal, de la Dirección de Literatura de la UNAM.

Esta nueva entrega da seguimiento a Imperfecta semejanza. Meditaciones y diálogos en torno a la traducción poética, publicado en la misma colección en 2015, libro en el que recoge ensayos y traducciones comentadas de las poetas en lengua inglesa Emily Dickinson, Marianne Moore, Elizabeth Bishop, Fanny Howe e Hilda Doolittle, así como una necesaria revisión de la traducción poética mexicana reciente.

En Imperfecta semejanza II, la autora nos introduce en su mundo de lecturas y afinidades literarias que, desde luego, tienen resonancia en su obra poética personal. Las escritoras alrededor de las cuales elabora su estética de la traducción comparten dos rasgos en común: su lenguaje poético complejo y único, que bien puede tener su oscuridad en las referencias culturales de la periferia rural de la que provienen varias de ellas, o bien, la sonora arquitectura de sus versos; y la profunda admiración de las poetas aquí reunidas hacia Emily Dickinson.

El libro se compone de siete capítulos: "Proemio" (en el que, por fortuna, aunque a regañadientes, traduce algunos fragmentos de la autora canadiense Anne Carson — probablemente una de las autoras de habla inglesa más conocidas actualmente en México-); "Susane Howe: telepatía entre lengua y lenguaje"; "Alice Oswald: fuente y caudal de la memoria"; "Louise Glück: entre enigmas y misterios"; "Lucie Brock-Broido: entre la magia real, la ficticia y la lingüística”; "C.D. Wright: entre la carne y el hueso, entre la palabra y el mundo, entre el aquí y el ahora, entre la primera y la tercera persona del singular (es decir) entre ella y yo, entre saber leer y saber escribir a fondo" y "Epílogo cantabile. Dionne Brand, contralto: escuchar es escribir".

A los márgenes de sus traducciones, que vienen acompañadas del texto fuente, López Colomé abreva sobre su proyecto de traducción para las obras y en cada una de las siete poéticas que conforman este libro, lo cual enriquece e ilustra 
su oficio y va formando lectores de traducciones de poesía. De igual manera, la autora ofrece un recorrido muy personal a lo largo de la trayectoria de cada escritora, seleccionando de aquí y allá los pasajes que se dispone a traducir y comentar.

En el capítulo sobre la estadounidense Susane Howe, la también traductora de Samuel Beckett, Berltolt Brecht y William Carlos Williams escribe sobre la escritura (y traducción) de fragmentos y plantea su traducción a partir del ejercicio poético propio de Howe: el embone sonoro de una palabra sobre otra dará la pauta para la elaboración del poema. Aquí reproducimos un fragmento de la traducción de "Melville's Marginalia", texto de la bostoniana: "If water is margined-imagined by the tender grass. / Marginal. Belonging to the brink or margent. / The brink or brim of anything from telepathy to poetry", es traducido como: "Si la hierba tierna imagina el agua al margen. / Si la hierba tierna imagina / margina el agua. / [Marginal. Perteneciente al borde o al coto.] / El borde o reborde de la telepatía a la poesía. / Poesía o telepatía, reborde del borde. / Un brote al margen de sauce y lirio. / Brote en la ribera, sauce, lirio /. Una pluma del borde del ala de un ave. / Una pluma borda el ala del ave." Aquí se puede observar cómo, con el fin de no dejar ninguno de los juegos posibles en español, Pura López Colomé opta por añadir versos, una especie de glosa a su propia traducción.

Estas poetas no dialogan solamente con López Colomé (con quien lo hacen de forma literal: la traductora visitó y sostuvo largas charlas en torno al quehacer poético con varias de ellas), sino que la mexicana las pone a conversar en las páginas de su libro.

Así como a Susan Howe le atormentaba que la relacionaran con la aclamada corriente de la language poetry, a Alice Oswald le aflige el culto alrededor del escritor. Su poesía vitalista es vehiculada por la literatura clásica, donde los personajes de las grandes epopeyas son puestos de nuevo ante sí, en pos de una justicia humana: "Y Héctor murió como todos los demás / tenía a su cargo a los troyanos / pero una lanza llegó a la parte blanca / entre clavícula y garganta / justo donde se aloja el alma del hombre".

Pura López Colomé describe a Louise Glück como "la suprema defensora de la sensualidad humana". Esta sensualidad se aplica en todos los sentidos, pero sobre todo al registro oral, algo que resulta un problema de traducción que López Colomé resuelve por medio del hipérbaton. Como ejemplo, reproducimos las dos primeras estrofas del poema titulado "End of Summer": "After all things occurred to me, / the void occurred me. // There is a limit / to the pleasure I had in form - ", el cual traduce del siguiente modo: "Después de ocurrírseme todo, / se me ocurrió el vacío. // Limitado fue / mi placer por la forma". 
De Lucie Brock-Broido, a quien dedica el capítulo más extenso del libro, Pura López Colomé destaca su sistemático rechazo y posterior aceptación - más a la fuerza que por gusto — de la academia, un rasgo que comparte con la misma traductora. El entendimiento de la poesía desde sus hilos filológicos la ayudó a depurar los zurcidos en su escritura, a borrar fronteras y marcas de agua que pudieran romper el universo de sus textos. "No soy una poeta difícil; sólo quiero que los vínculos importantes entre las cosas sean invisibles”, afirma Brock-Broido en este recorrido a lo largo de su trabajo.

Así, la autora prosigue su análisis de la obra de estas escritoras, quienes forman el canon femenino de la poesía en lengua inglesa. Si acaso se le puede reprochar algo a este libro es su desapego a ciertos autores fundamentales dentro de este tipo de estudios - pienso en Antoine Berman, quien desarrolló una estética de la traducción a partir de George Gadamer-. Pura López Colomé se refugia en esa lengua poética de la que habla Walter Benjamin y en las destellantes demarcaciones en torno a la traducción de George Steiner y Borges, en donde el texto meta es, de alguna forma, el lado oscuro del poema en sí mismo y no únicamente un desplazamiento del soporte hacia otro sistema lingüístico y cultural. A pesar de esto, sí plantea y discute abiertamente problemas de traducción que, sin duda, pueden enriquecer un análisis riguroso sobre su trabajo.

Quizá también se deba a dicho desapego, la soltura, el asombro y la dilucidación poética de estos ensayos, que pueden ir de lo biográfico a lo metafísico sin descuidar la delicada orfebrería en torno a la traducción poética. Ojalá que haya un tercer volumen de Imperfecta semejanza próximamente, una saga que puede ser un gran pilar en la historia de la traducción de poesía escrita y traducida por mujeres en México.

\section{REFERENCIAS}

López Colomé, Pura (2015), Imperfecta semejanza. Meditaciones y diálogos en torno a la traducción poética, México, Literatura UNAM.

López Colomé, Pura (2018), Imperfecta semejanza II. In nomine vocis. Ulteriores meditaciones en torno a la traducción poética, México, Literatura UNAM. 
Xitlalitl Rodríguez-Mendoza

Pura López Colomé y su traducción del canon femenino de la poesía en lengua inglesa

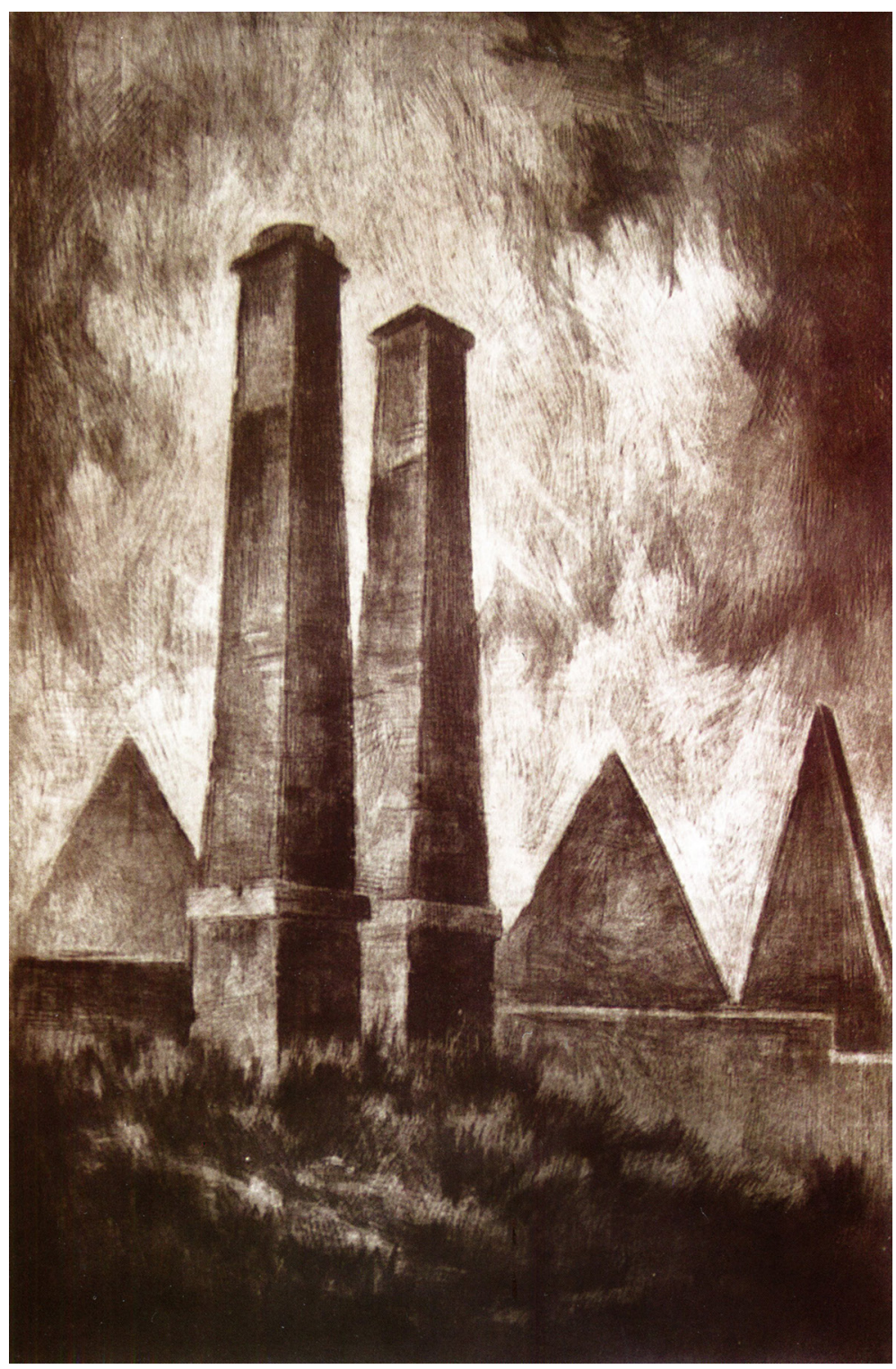

Chimeneas (s/f).Mezzotinta: Jesús Gallardo.

Prohibida su reproducción en obras derivadas.

Xitlalitl Rodríguez Mendoza. Escritora y editora mexicana. Licenciada en Letras Hispánicas por la Universidad de Guadalajara (UDG), México. Ha sido becaria del Fondo Nacional para la Cultura y las Artes FONCA en dos ocasiones. Obtuvo el Premio Nacional de Poesía Ignacio Manuel Altamirano 2015. Autora de cinco libros. Ha colaborado en diferentes revistas literarias de México y del extranjero. Pertenece al consejo editorial de la revista Reverso y es editora de Vice. 